\title{
RESSOCIALIZAÇÃO: O DESAFIO DA EDUCAÇÃO NO SISTEMA PRISIONAL FEMININO
}

\author{
Elizangela Lelis DA CUNHA*
}

\begin{abstract}
RESUMO: Este artigo é fruto da pesquisa de doutorado em andamento e tem como objetivo discutir, por meio da perspectiva da representação social e dos direitos humanos, o tema da exclusão e ressocialização de mulheres reeducandas, buscando apreender qual o papel do processo educativo institucional na ressocialização dessas mulheres.
\end{abstract}

Palavras-chave: Ressocialização. Educação. Mulheres. Prisão.

\section{RESOCIALIZATION: THE CHALLENGE TO EDUCATE WOMEN IN THE DETENTION SYSTEM}

\begin{abstract}
This paper stems from an on-going scientific research for a doctor's degree. From the perspective of social representation and human rights, it discusses the exclusion and resocialization of women that are being reeducated. It tries to determine the role of the institutional education process in the re-socialization of these women.
\end{abstract}

Key words: Resocialization. Education. Women. Prison.

Doutoranda do Programa de Pós-Graduação em Educação Escolar da Faculdade de Ciências e Letras, da Universidade Estadual Paulista "Júlio de Mesquita Filho" (UnEsp, Campus de Araraquara).E-mail: elizlelis@yahoo.com.br 


\section{Introdução}

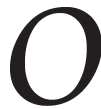

sistema prisional feminino brasileiro vem sofrendo, nas últimas décadas, um aumento considerável no número de atendimento. Apesar do número de mulheres apenadas ser consideravelmente inferior ao de homens presos, este número tem crescido nas últimas décadas. A configuração da prisão como espaço de encarceramento dos desviantes e punição de seus crimes tem ganhado espaço na concepção da sociedade moderna capitalista, além do espaço historicamente disciplinar do caráter da pena. Essa política de encarceramento em massa reflete, pois, as consequências de uma sociedade capitalista que marginaliza grande parte da população: enquanto, por um lado, acumula riqueza, por outro, miséria, incerteza, desesperança e violência.

\section{O desenvolvimento capitalista e a questão prisional}

O desenvolvimento preconizado pela sociedade capitalista esteve amparado na economia, ou seja, no aumento de riquezas materiais. Tal processo garantiu progresso considerável na ampliação tecnológica e no bem estar de parcela da sociedade. Em contrapartida, provocou extremos de privação, pobreza e marginalização social para grande parcela da população dessa mesma sociedade. Segundo Martins (2008, p. 10-11):

Esse desenvolvimento anômalo não se manifesta apenas nas privações que produz e dissemina. Manifesta-se, também, nas estratégias de sobrevivência por meio das quais os pobres teimam em fazer parte daquilo que não os quer, senão como vítimas e beneficiários residuais de suas possibilidades. Nessas estratégias nem sempre compatíveis com o bem comum, no recurso ao ilegal e ao anti-social por parte das vítimas, a sociedade inteira é alcançada e comprometida nas compreensíveis ações de sobrevivência daqueles aos quais ela não oferece a apropriada alternativa de vida. Porque, não nos iludamos, o capitalismo que se expande à custa da redução sem limites dos custos do trabalho, debitando na conta do trabalhador e dos pobres o preço do progresso sem ética nem princípios, privatiza ganhos nesse caso injustos e socializa perdas, crises e problemas sociais. Por diferentes caminhos, essas deformaçōes se disseminam, penalizando a todos e não só a alguns, até mesmo aos principais beneficiários desse modo de produzir e acumular riquezas. 
O autor alerta para os efeitos desumanizantes do processo capitalista de produção que, ao reduzir a participação da maioria da população trabalhadora tanto no que se refere à disponibilidade de trabalho como ao usufruto dos bens produzidos, produz marginalização social e miséria. Essa classe marginalizada busca, de diferentes formas, estratégias de sobrevivência, o que nem sempre está em consenso com a ordem social estabelecida.

A miséria que se estabeleceu na sociedade atual capitalista não se refere somente à privação da grande maioria dos trabalhadores aos bens materiais produzidos, ou seja, ao fator econômico. A miséria está na coisificação desse trabalhador e na sua marginalização em relação ao sistema, que já não necessita totalmente de sua mão de obra. A exclusão social se refere à perda da identidade do trabalhador, à completa ausência do sentimento de pertencimento e de esperança de que as coisas possam se reverter.

A descrença atinge grande parte dos trabalhadores, os quais, em situação de miséria e marginalização, se submetem a trabalhos precários em condiçôes precárias, com salários que não subsidiam nem a sua mão de obra, ou seja, aceitam uma inclusão indigna da condição de ser humano.

A desumanização do trabalhador provocada pela sociedade e seu sistema capitalista de produção, onde o principal objetivo é o acumulo de riqueza a qualquer custo, traz para essa mesma sociedade conflitos de ordem econômica, social e política, cujas principais expressóes são a violência e o medo.

A violência objetiva-se, hoje, não somente na agressão física, mas também por meio da violência simbólica, ${ }^{1}$ no medo, no temor que enfrentamos daquilo que está oculto e que não vemos. Para Adorno (2000, p. 99), a partir de 1985 houve um aumento considerável da violência em nossa sociedade, o que provocou um sentimento coletivo de medo e insegurança e "(...) as prisões não constituem instrumentos de reeducação de cidadãos condenados pela justiça”.

Buscar formas de lidar com esta violência e de amenizar seus prejuízos sociais é essencial na luta pela construção de uma sociedade justa, principalmente quando assistimos à sociedade, desprotegida e insegura com o aumento de homicídios, sequestros, roubos e da violência em geral, apoiar atos violentos, acreditando que somente com 
repressão e ampliação do numero de instituições prisionais é que terão ordem e paz social.

Nesse sentido, repensar a conduta das instituições penais que se propõem a recuperar, reeducando, seus internos e suas internas, é de fundamental importância, já que somente com oportunidades concretas de reinserção social, enquanto sujeitos de direitos, é que será possível a cada um deles construir novos caminhos.

\section{Contexto social brasileiro: a questão da mulher e da exclusão}

Para compreender o sistema prisional feminino brasileiro e como a educação recebida pelas apenadas interfere no processo de ressocialização, não podemos perder de vista o contexto econômico, social e político vivenciado por estas, tanto no que se refere às condições materiais e objetivas de vida como nos fatores subjetivos, de inserção social, ética e política das mulheres na sociedade atual, cerceadas pela relação de poder estabelecida historicamente entre homens e mulheres.

A construção do papel feminino no imaginário social esteve atrelada ao processo histórico desenvolvido pela humanidade durante o desenvolvimento de seus saberes. E como assinala Foucault (2007b), a produção de saberes pela humanidade, por meio do processo de construção material e social da vida, determinou no decorrer evolutivo das sociedades o grau de poderes, ou seja, o poder, tanto material quanto ideológico, de uma classe sobre as outras esteve estritamente ligado ao grau de conhecimento científico que a primeira possuía sobre as demais.

$\mathrm{Na}$ questão de gênero, esse fator sempre foi determinante na definiçãao das relações entre os sexos, pois o grau de submissão, de sujeição e inferioridade que as mulheres vivenciaram durante séculos esteve também amparado no conhecimento divulgado sobre estas, constantemente associadas às categorias desviantes e inferiores.

$\mathrm{O}$ advento da sociedade moderna capitalista e o processo de urbanização e industrialização fizeram com que as mulheres fossem recrutadas para o mercado de trabalho. Essa nova configuração possibilitou a ampliação da participação da mulher no meio social, bem como o aumento de sua escolaridade. Tal possibilidade, embora com grandes resistências sociais, fez com que, a partir dos anos de 1920, nascessem 
as primeiras manifestações femininas no Brasil. Como descrevem Pascal \& Schwartz (2006), a partir da década de 20, as mulheres passam a perceber a importância de se ter direitos e lutar pela ampliação de sua cidadania no país.

Por décadas, a mulher ficou restrita ao espaço privado e, nele, à produção e reprodução da força de trabalho e das relações sociais de produção. Na família, a mulher era responsável por produzir a força de trabalho, internalizando normas e interiorizando ideologias, tendo como papel principal a formação da personalidade dos filhos, por meio da reprodução de valores, além de servir ao capital enquanto infraestrutura, por meio do trabalho doméstico não remunerado que, por sua vez, contribui para o barateamento da mão de obra ao capital. $^{2}$

A mudança nos papéis sociais desempenhados por homens e mulheres observa-se tanto pela necessidade de mão de obra feminina e barata ao mercado, quanto pelo agravamento das condições materiais impostas pelo sistema capitalista às famílias, que, para sobreviverem, têm se reestruturado e lançado maior número de membros no mercado de trabalho, inclusive mulheres. É neste aspecto que ocorre a transformação cultural, já que o homem não se constitui mais o único provedor das necessidades do grupo familiar e à mulher impóe-se uma dupla exploração da força de trabalho, ou dupla jornada $(\mathrm{Cu}$ nha, 2007).

A mulher, que historicamente vivenciou uma trajetória de invisibilidade como sujeito no espaço público e subordinação no âmbito privado, passou a assumir novos papéis sociais com a transformação da sociedade capitalista e a disputar o poder nas relaçóes que estabelece, inclusive na esfera doméstica, como chefe de família, ${ }^{3}$ e no espaço público, por meio do trabalho assalariado.

Brito (1996, apud Neves, 1999) reconhece que o trabalho feminino assalariado pode ser apontado como particularmente contraditório, uma vez que favorece a vivencia da exploração, da dominação e do seu caráter penoso, mas também pode ser percebido como alternativa à possibilidade de acesso a conquistas e prazeres, que, sem ele, nem sequer poderiam ser almejados. Em outras palavras, poderíamos afirmar que se trata de um espaço de reprodução das relaçóes de gênero e, ao mesmo tempo, de um canal para a desconstrução dessas relações. 
Por outro lado, as mulheres e os homens vivenciam hoje, no contexto hegemônico do neoliberalismo, a geração de riquezas pelo sistema de produção capitalista, que não são socializadas pela maioria das pessoas, o aumento do desemprego ou o fim da promessa de emprego pleno, aumentando a desigualdade e a exclusão.

No cenário nacional a violência atinge índices elevados e ampla notoriedade. A sensação de insegurança e impotência frente a esse fenômeno incentiva a opinião pública, influenciada pela mídia, principalmente televisiva, a clamar por mais repressão. Assim, a restrição da liberdade apresenta-se como principal forma de punição e tratamento para os infratores nas sociedades atuais. Assistimos a um aumento considerável da população carcerária no Brasil, e as mulheres, ainda que em menor número e com aspectos diferenciados, também alimentam essas estatísticas (Braunstein, 2007).

No Brasil, segundo dados aproximados, entre $70 \%$ e $80 \%$ dos presos que saem sob o regime de liberdade condicional retornam ao chamado "mundo do crime" e voltam a ser novamente presidiários, com a denominação de "reincidentes". No "mundo de fora", sofrem todos os tipos de estigmas (Carvalho Filho, 2005). Como demonstra este autor (op. cit.), o índice de reincidentes nas prisões brasileiras é altíssimo, o que confirma a pouca efetividade do papel ressocializador e educador pretendido por estas instituições.

Alem disso, segundo Silva (1997, p. 176) "os efeitos mais duradouros do processo de institucionalização são os danos causados à constituição da identidade, a afirmação do 'estigma', a incorporação do sentimento de inferioridade e a redução significativa da autoestima”. Tais consequências tendem a se agudizar quando se trata de mulheres infratoras no contexto de reinserção social, uma vez que esse processo de estigmatização se intensifica, na medida em que a ele se soma o sexismo $^{4}$ vivenciado por estas em suas relações sociais cotidianas.

\section{Estigma e exclusão}

A estigmatização se configura como uma das consequências mais dolorosas que as pessoas que cumprem ou cumpriram pena em instituições fechadas enfrentam, quando são reinseridas no convívio social. 
Quando nos referimos às mulheres apenadas, a estigmatização sofrida pelo fato de já possuírem passagem pela prisão se associa ao sexismo e seus estereótipos, contribuindo para que o domínio do poder masculino prevaleça sobre as relações e reafirmando o sentimento de inferioridade e submissão feminina.

O conceito de estigma a que estamos nos referindo é definido por Goffman (1978, p. 7) como "a situação do indivíduo que está inabilitado para a aceitação social plena". O estigma compreende desde os sinais corporais, como marcas ou defeitos físicos, até a forma preconceituosa de tratar o desvio.

Diante do processo de perda de identidade do sujeito e do individualismo exacerbado que o sistema capitalista de produção tem causado, esse processo de estigmatização vivenciado pela mulher infratora poderá levar à sua autoculpabilização pelo fracasso nos papéis sociais previamente definidos e atribuídos culturalmente. Nesse processo, ela é incapaz de perceber todas as implicações sociais que contribuíram para colocá-la nesta condição.

O processo de ressocialização deve abranger, necessariamente, os aspectos que envolvem a construção da imagem da mulher, concreta e subjetiva, o papel da educação, da qualificação e do trabalho no cárcere.

\section{A prisão enquanto mecanismo de punibilidade e cuidado}

Entendida e classificada por Goffman (1978) como "instituição total", 5 a prisão se configura, na sociedade moderna, especialmente após o século XIX, como o principal mecanismo de punição do sistema de execução penal, cuja privação dos direitos e da liberdade caracteriza o grau de punibilidade da nova forma de administrar juridicamente as penas e seu grau de efetividade junto aos desviantes.

A substituição da pena no decorrer da história, dos suplícios que atingiam o corpo e causavam sofrimento físico para a punição disciplinar por meio da privação da liberdade e a clausura vigiada, passa agora a se constituir em uma violência simbólica a favor do castigo e correção dos presos e presas. Para isso,

(...) um exército inteiro de técnicos veio substituir o carrasco, anatomista imediato do sofrimento: os guardas, os médicos, os capelães, os psiquiatras, 
os psicólogos, os educadores; por sua simples presença ao lado do condenado, eles cantam à justiça o louvor de que ela precisa: eles lhe garantem que o corpo e a dor não são os objetos últimos de sua ação punitiva (...). (Foucault, 2007a, p. 14)

Como se refere Foucault (op. cit.), essa passagem de uma pena a outra não se configura em "penalidade indiferenciada, abstrata e confusa", mas na mudança de uma "arte de punir" à outra, não menos científica que a primeira. A punição agora se alastra sobre o íntimo do apenado, por meio de técnicas disciplinares encarregadas de fazer cumprir o critério de punibilidade; da correção e reeducação, estas técnicas devem dar conta do cuidado para com o preso e a presa, visando seu encaminhamento e treinamento para novas atividades que os distanciem do crime e que os aproximem do trabalho do mundo capitalista.

Verificamos que, no decorrer da história, o tratamento dado aos presos e presas esteve atrelado ao modelo social vigente, ou seja, os suplícios deixaram de ser necessários a partir do momento em que o infrator passou a ser considerado uma possibilidade de mão de obra para a nascente sociedade capitalista da época. A visão frente aos apenados, a partir da tomada burguesa do poder, passou a ser de que estes se configuravam em um bem social e, como tal, eram úteis ao sistema enquanto mão de obra para produção da riqueza.

A preocupação com a humanização da pena, além do caráter utilitário atribuído ao apenado pelo sistema capitalista burguês de produção, tem sua origem no fato de que, após a Revolução Francesa, a discussão sobre os direitos humanos foi impulsionada por diversos setores da sociedade, que passaram a cobrar das autoridades a redução da arbitrariedade e a humanização das penas.

Com o advento da burguesia no poder, a preocupação era a redução da criminalidade social e, para isso, a prisão não se configurava um exemplo eficaz de inibição dos atos socialmente condenáveis. Contudo, no decorrer dos tempos, assistimos a essa preocupação dando lugar a um investimento considerável nesse modo de punição e, em pouco tempo, a prisão se tornou o mecanismo mais comum de punição aos desviantes na sociedade moderna.

Destarte, na sociedade moderna, a prisão passa a ser o local entre o mundo da criminalidade e o restante da sociedade. Nessa perspectiva, 
a prisão se configura como o aparelho administrativo do Estado com a função de modificar os condenados em seu foro mais íntimo, fazendo com que estes retornem ao convívio social teoricamente ressocializados e reeducados. Para Adorno (2006, p. 214) “a prisão é uma máquina de produzir 'corpos dóceis' - economicamente produtivos e politicamente neutralizados em sua capacidade de revolta e resistência”.

Essa formação de "corpos dóceis" ocorre, como já dissemos, pelo efeito da disciplina enquanto modelo de correção e controle. Segundo Foucault (2007a, p. 163), esta disciplina se configura em:

(...) espaço fechado, recortado, vigiado em todos os seus pontos, onde os indivíduos estão inseridos num lugar fixo, onde os menores movimentos são controlados, onde todos os acontecimentos são registrados, onde um trabalho ininterrupto de escrita liga o centro e a periferia, onde o poder é exercido sem divisão, segundo uma figura hierárquica contínua (...).

A disciplina se configura em um dispositivo que visa a distribuição dos corpos no espaço, a partir de uma técnica que age sob o íntimo dos apenados. Para que esse sistema funcione, o controle deve ser exercido rigidamente durante todo o cotidiano de cada indivíduo apenado. Tal mecanismo se expressa na regulamentação de horários e rotinas, como a delimitação do tempo para oficinas pedagógicas, culturais e profissionalizantes, além dos exercícios físicos, por meio de atividades repetitivas e diferentes no chamado "tempo livre".

A vigilância exercida na prisão por meio da disciplina assume duplo sentido para garantir a eficácia. De acordo com Foucault (2007a), para que o poder disciplinar atinja seu objetivo de adestramento dos corpos e se aproprie totalmente de sua utilidade, este deve garantir a vigilância hierárquica, por meio da arquitetura prisional, e a vigilância normatizada, por meio de privilégios que visam marcar os desvios e hierarquias, ao mesmo tempo em que castigam e recompensam.

O acompanhamento técnico, por meio de relatórios de desenvolvimento de conduta, evolução e situação da apenada desde seu ingresso na instituição, tem por objetivo integrar esse método do poder disciplinar, contribuindo para a evolução positiva no tratamento oferecido pela instituição, bem como para a distribuição de privilégios. 
A produção de "saberes" realizada pelo papel da normalização faz com que o sistema prisional, por meio de sua ação disciplinadora e reguladora, obtenha uma rede de "poderes" sobre o corpo e a vida do interno.

As prisões, sob a ótica da ressocialização entre muralhas, hoje se configuram em espaço físico onde o Estado consolida e legitima sua política pública de controle e repressão aos desviantes. Para a sociedade, as prisões estão legitimadas como espaço pedagógico necessário de punição e de proteção a sua própria segurança e sobrevivência.

A retórica que atribui à prisão o papel de um espaço de cuidado e proteção, em uma visão mais crítica e desmistificadora, a desvela como espaço meramente punitivo e homogêneo, voltado ao controle disciplinar e punitivo dos internos e internas desiguais, sejam eles e elas marcados por diferenças de nível socioeconômico, de gênero, étnico-racial ou de acesso à escolaridade, à informação etc.

Fazendo um balanço dos danos que as instituições totais podem causar à vida de quem é submetido a esse método de correção, Silva (1997, p. 176) assinala que "os efeitos mais duradouros de processo de institucionalização são os danos à constituição da identidade, a afirmação do 'estigma', a incorporação do sentimento de inferioridade e a redução significativa da autoestima".

Segundo Braunstein (2007), o conceito de punibilidade, na perspectiva da dominação e do controle social, se relaciona diretamente com o cuidado de alguém ou de alguns em detrimento do sofrimento de outro. Dessa forma, o autor sugere que é sempre necessário perguntar: "para cuidado de quem? Para cuidado de que? Quem mereceria, ou deveria ser sujeito em relação à ação de ser cuidado? Quem é que deve ou merece ser punido? Quem pode punir, de que forma, em que medida?” (p. 29). Com estes questionamentos, Braunstein traça uma linha de raciocínio lógico do dever cuidar e do querer cuidar frente à concepção amparada pela Declaração dos Direitos Humanos de 1948, que assegura a todo ser humano o direito a ter direitos e, como tal, a receber o cuidado. Assim, concordando com o autor:

(...) é fundamental enfatizar o paradigma desta reflexão, que considera inaceitável qualquer suposto mecanismo de controle social que justifique 
o extermínio, a exploração ou a não consideração do outro(s) como significativos de cuidado na esfera do dever cuidar (...). (Braunstein, 2007, p. 29-30)

A perspectiva dos direitos humanos assegura o direito de todos ao cuidado, sem distinção de raça, gênero ou situação socioeconômica. No entanto, por diversas vezes na história da humanidade, em contextos de dominação, verificamos o cuidado sendo estabelecido numa perspectiva utilitarista e exploratória para pessoas coisificadas. ${ }^{6}$

Tendo como perspectiva a ressocialização, algumas questões que devemos colocar em pauta são: o que tem a ver a educação com esse panorama? Quais as possibilidades que esta mesma educação pode oferecer às mulheres que vivenciam esse processo de aprisionamento?

\section{Algumas considerações sobre o papel da educação no processo de ressocialização}

A educação escolar formal se estabeleceu na sociedade moderna como espaço legítimo de transmissão de conhecimento e formação intelectual das crianças, ou seja, por meio dessa instituição as famílias delegam a educação e formação dos filhos. É nesse espaço formal que é transmitido o conhecimento historicamente adquirido pela humanidade e a criança vai se preparando para assumir as responsabilidades da vida adulta e enfrentar o mercado de trabalho.

$\mathrm{Na}$ legislação brasileira, os pais que não matricularem seus filhos no ensino básico formal, em idade apropriada, podem responder juridicamente por seu ato. O Estatuto da Criança e do Adolescente (Lei n. 8.069 de 13/07/1990) garante a participação de todos na educação obrigatória.

Apesar das garantias jurídicas, sabemos que na realidade há diversos fatores que influenciam no fracasso escolar de muitas crianças e jovens. Entre eles, estão a precária condição socioeconômica de considerável parcela da população - o que ocasiona um déficit cultural, em virtude da pouca ou completa falta de acesso aos bens culturais da humanidade e à linguagem formal propagada na instituição escolar e a qualidade da educação oferecida pelo setor público, amplamente criticada pelos seus baixos índices de aproveitamento dos educandos. 
A baixa escolaridade, mesmo com o aumento do acesso à educação escolar nas últimas décadas, ainda se constitui realidade entre a maioria da população brasileira e nos alerta para a forte ligação que ela estabelece com a criminalidade. Entre a população carcerária do país, os índices são bastante expressivos e esta realidade não seria diferente no Centro de Ressocialização Feminino (CRF) de Araraquara: mesmo se localizando em um dos estados mais desenvolvidos, é baixo o índice de escolaridade entre as reeducandas em cumprimento de pena.

O CRF de Araraquara tem capacidade para 96 presas. Em outubro de 2009, quando iniciamos a primeira fase da pesquisa de doutorado, intitulada "Mulheres reeducandas em processo de ressocialização: o desafio da educação", havia 93 mulheres em cumprimento de pena, em regime fechado ou semiaberto. Desse total, 78 aceitaram participar da pesquisa e responderam ao questionário aplicado. Destas 78 mulheres presas, 51 cumpriam pena em regime fechado e 27 estavam em regime semiaberto.

De acordo com as informaçôes obtidas por meio do questionário escrito, a maioria das mulheres estava na faixa etária entre 19 a 39 anos, como podemos observar na tabela a seguir:

\section{Tabela 1}

\begin{tabular}{|c|c|c|c|c|c|c|}
\hline Quantidade de mulheres cumprindo pena no CRF de Araraquara, segundo a idade - outubro \\
de 2009
\end{tabular}

Como se pode verificar, das 78 mulheres reeducandas que responderam ao questionário, 63 estão na faixa etária entre 19 e 39 anos, o que significa $80,76 \%$. Tal percentagem indica que a maioria das internas estava em idade laborativa.

Com relação à escolaridade antes da prisão e até a data da pesquisa, temos a seguinte realidade a partir das respostas, na próxima tabela: 


\section{Tabela 2}

\begin{tabular}{|c|c|c|c|c|c|c|c|}
\hline \multicolumn{6}{|c|}{ Escolaridade das reeducandas antes e depois da prisão - referência do CRF de Araraquara, em outubro de } \\
2009 & Analfabeta & $\begin{array}{c}\text { Fundamental } \\
\text { incompleto }\end{array}$ & $\begin{array}{c}\text { Fundamental } \\
\text { completo }\end{array}$ & $\begin{array}{c}\text { Médio } \\
\text { incompleto }\end{array}$ & $\begin{array}{c}\text { Médio } \\
\text { completo }\end{array}$ & $\begin{array}{c}\text { Superior } \\
\text { incomp. }\end{array}$ & $\begin{array}{c}\text { Superior } \\
\text { completo }\end{array}$ \\
\hline $\begin{array}{c}\text { Número de } \\
\text { mulheres }\end{array}$ & 1 & 51 & 7 & 10 & 5 & 2 & 2 \\
\hline $\begin{array}{c}\text { Escolaridade } \\
\text { antes da } \\
\text { prisão }\end{array}$ & 1 & 49 & 6 & 12 & 7 & 2 & 2 \\
\hline $\begin{array}{c}\text { Escolaridade } \\
\text { em outubro } \\
\text { de 2009 }\end{array}$ & 0 & & & & & & \\
\hline
\end{tabular}

Observando estes dados, podemos constatar a baixa escolaridade da população feminina que se encontra em cumprimento de pena no CRF de Araraquara, realidade da maioria das presas brasileiras. De acordo com os dados, $66,66 \%$ das apenadas não tinham completado o ensino fundamental quando foram presas; $8,97 \%$ tinham o ensino fundamental completo, $6,41 \%$ tinham o ensino médio completo e somente $2,56 \%$ tinham concluído o ensino superior.

$\mathrm{Na}$ última linha da mesma tabela temos também representada a evolução educacional obtida pelas reeducandas na prisão, durante o processo de ressocialização. De acordo com os dados, houve uma redução do número de mulheres com escolaridade fundamental incompleta, de $66,66 \%$ para $62,82 \%$, o que refletiu em uma elevação do grau de escolaridade destas, atingindo o ensino fundamental completo e a progressão para a etapa seguinte. Verificamos também uma elevação do número de mulheres com ensino médio completo: de $6,41 \%$ para $8,97 \%$.

A realidade educacional das mulheres que cumprem pena no CRF de Araraquara reflete a situação das demais instituições prisionais do estado e do país. Mesmo que os dados estatísticos sobre educação penitenciária sejam insuficientes para estabelecermos um diagnóstico sobre a situação em todo o país, os dados do estado de São Paulo são ilustrativos. De acordo com a Fundação de Amparo ao Trabalhador Preso (Funap), conhecida como "Fundação Prof. Dr. Manoel Pedro 
Pimentel", "em novembro de 2005, 47,53\% da população carcerária trabalhavam e $17,02 \%$ estudavam, em dezembro do mesmo ano, cerca de $78 \%$ da população masculina e $69 \%$ da população feminina eram analfabetas ou possuíam ensino fundamental incompleto" (FUNDAP, 2010).

A evolução educacional no CRF ainda é inexpressiva, mas já reflete a ação educacional institucional, pois a maioria das mulheres reeducandas está frequentando as aulas promovidas pelo Programa do Preso, que visa promover a educação do preso, proporcionando escolaridade de ensino fundamental e médio, promovendo a formação profissionalizante, geração de renda, cultura e esporte, apoio ao sustento e à liberdade. O Programa é coordenado pela FUNAP.

De acordo com o Estatuto da FUNAP (Decreto n. 10.235, de 30 de agosto de 1977), no seu artigo 4o: "A Fundação terá por objeto contribuir para a recuperação social do preso e para a melhoria de suas condições de vida, através da elevação do nível de sanidade física e moral, do adestramento profissional e do oferecimento de oportunidade de trabalho remunerado (...)". O Estatuto estabelece sua contribuição na elevação do nível de sanidade física e moral, mas não esclarece o que está considerando como "sanidade física e moral", da mesma forma que utiliza o termo "adestramento profissional" dos presos e presas. Nosso questionamento refere-se ao por que deste e não de outro termo a ser usado no documento, uma vez que "adestramento" é amplamente empregado para a submissão de animais, para impor algo àqueles desprovidos de poder para questionar.

No CRF de Araraquara, a FUNAP é responsável pelo programa educacional, desenvolvido com docentes monitoras do próprio quadro de reeducandas. O programa de formação de educadoras presas tem como perspectiva de sucesso o fato de que, por elas já fazerem parte da realidade prisional e conhecerem a linguagem das apenadas, consigam maior eficácia no processo de ensino-aprendizagem. Porém, o que fica mais aparente nessa política é a redução de gastos, uma vez que essas reeducandas não possuem formação específica para o exercício, sua orientação é feita em duas horas diárias, por uma estagiária de nível superior contratada pela Fundação para coordenar o programa e ajudá-las na preparação das aulas. Tal questão deveria ser ponto de discussão e avaliação das reais intenções da ação educativa 
dentro dessa instituição total, uma vez que o rodízio da coordenação é amplo, até mesmo em virtude das condiçôes de trabalho e contrato temporário de estagiário, o que prejudica o desenvolvimento qualitativo do projeto educativo.

A falta de oportunidade de escolaridade na idade adequada é bastante relevante na população carcerária do CRF de Araraquara e acompanha o alto índice de inserção no mercado de trabalho antes da maioridade. Vejamos na tabela a seguir:

\section{Tabela 3}

\begin{tabular}{|c|c|c|c|c|c|c|c|c|}
\hline \multicolumn{2}{|c|}{ Idade e vínculo do primeiro emprego das reeducandas do CRF de Araraquara - outubro de } \\
2009
\end{tabular}

Como podemos observar, $86 \%$ de 78 mulheres que participaram da pesquisa iniciaram no mercado de trabalho antes dos 18 anos de idade. Destas, $83,58 \%$ estavam no mercado informal, ou seja, sem direitos trabalhistas e previdenciários garantidos.

A última tabela reflete a realidade perversa que atinge uma parcela considerável da população brasileira, que tem seus direitos educacionais prejudicados devido à situação socioeconômica familiar que exige, desde cedo, a inserção do maior número de pessoas no mercado de trabalho para garantia do sustento da unidade de consumo. A condição de miserabilidade e exclusão social vivenciada pela maioria da população a torna vulnerável ao cumprimento de pena, uma vez que, ao cometerem o delito, por não terem conhecimento nem recursos para contratar bons defensores, acabam na cadeia, cumprindo penas que, muitas vezes, poderiam ser reduzidas em virtude da pouca relevância do delito. Porém, a morosidade da 
justiça e a pouca disposição da sociedade para resolver os problemas criados por ela mesma levam a essa criminalização da pobreza.

A informalidade do primeiro emprego reflete, no decorrer dos anos, na precária inserção social que essas mulheres e suas famílias vivenciam tanto no que diz respeito às condiçôes materiais de marginalização, como às condiçôes subjetivas de pertencimento e construção de identidade.

Vejamos, na tabela a seguir, o primeiro emprego das mulheres reeducandas do Centro de Ressocialização Feminino de Araraquara:

\section{Tabela 4}

\begin{tabular}{|l|c|c|}
\hline \multicolumn{3}{|c|}{$\begin{array}{c}\text { Distribuição de mulheres do CRF de Araraquara, segundo atividade do primeiro } \\
\text { emprego }\end{array}$} \\
\hline Primeiro emprego & Número & $\%$ \\
\hline Recepcionista & 1 & $1,28 \%$ \\
\hline Estagiária & 1 & $1,28 \%$ \\
\hline Proprietária de escola de informática & 1 & $1,28 \%$ \\
\hline Salgadeira & 2 & $2,56 \%$ \\
\hline Babá & 19 & $24,35 \%$ \\
\hline Vendedora/comércio & 5 & $6,41 \%$ \\
\hline Doméstica & 18 & $23,07 \%$ \\
\hline Trabalhadora rural & 9 & $11,53 \%$ \\
\hline Setor industrial & 1 & $1,28 \%$ \\
\hline Funcionária pública & 1 & $1,28 \%$ \\
\hline Técnica de enfermagem & 1 & $1,28 \%$ \\
\hline Serviços gerais & 1 & $1,28 \%$ \\
\hline Confecção & 3 & $3,84 \%$ \\
\hline Garçonete & 3 & $3,84 \%$ \\
\hline Patrulheiro (menor aprendiz) & 1 & $1,28 \%$ \\
\hline Ajudante de cozinha & 1 & $2,56 \%$ \\
\hline Artesã & 10 & $1,28 \%$ \\
\hline Bordadeira & $1,28 \%$ \\
\hline Não especificado & $12,82 \%$ \\
\hline Total & 1 & $100,00 \%$ \\
\hline & 1 & \\
\hline & 1 & 1 \\
\hline
\end{tabular}


Podemos verificar que a maioria das mulheres teve, como primeiro emprego, funçōes de pouco destaque público e baixa remuneração, que representavam uma extensão do lar e do papel feminino desenvolvido por esta na esfera privada, na maioria das vezes, exercidas na informalidade, sem garantias dos direitos trabalhistas.

As profissões ou funções mais exercidas como primeiro emprego pelas mulheres presas foram: doméstica, babá e trabalhadora rural. Estas três somam $58,95 \%$ do total do primeiro emprego declarado pelas mulheres presas.

Outro dado significativo e impactante na realidade socioeconômica das mulheres presas, bem como no fator emocional após a prisão e separação familiar, se refere à maternidade. Vejamos, na tabela a seguir, a incidência de filhos entre as apenadas do CRF de Araraquara:

\section{Tabela 5}

\begin{tabular}{|l|c|c|}
\hline \multicolumn{2}{|c|}{$\begin{array}{c}\text { Distribuição de mulheres presas no CRF de Araraquara, segundo a maternidade e idade } \\
\text { dos filhos - outubro de 2009 }\end{array}$} \\
\hline Idade dos filhos & Número de mulheres & $\%$ \\
\hline Até 12 anos & 43 & $35,12 \%$ \\
\hline De 13 a 18 anos & 24 & $14,10 \%$ \\
\hline Entre 19 a 21 anos & 11 & $23,07 \%$ \\
\hline Acima de 21 & 18 & $6,41 \%$ \\
\hline Não especificou & 5 & $\mathbf{8 7 , 1 7 \%}$ \\
\hline Total de mães & $\mathbf{6 8}$ & $\mathbf{1 2 , 8 2 \%}$ \\
\hline Não tem filhos & $\mathbf{1 0}$ & $30,76 \%$ \\
\hline
\end{tabular}

Esta tabela nos transmite a quantidade de mulheres mães e as idades de seus filhos. Como podemos observar, $87,17 \%$ das apenadas do CRF são mães e $55,12 \%$ das 78 mulheres possuem filhos até 12 anos. 
A associação dos fatores: pouca escolaridade devido ao ingresso precoce no mercado de trabalho, na maioria das vezes, no setor informal e em funçôes de subemprego, e a maternidade também precoce faz parte da realidade da maioria das mulheres em cumprimento de pena no CRF de Araraquara, o que amplia o grau de vulnerabilidade emocional destas, trazendo demandas de cunho subjetivo para o programa educacional desenvolvido, que influenciam consideravelmente na aprendizagem e interesse das internas.

A responsabilidade pelo sustento da família, principalmente das reeducandas que possuem filhos, é um fator que traz considerável preocupação e sofrimento emocional. Muitas encaminham quase todo o dinheiro que recebem do trabalho realizado na prisão para os familiares.

A quantidade de filhos por mulheres também é considerável fator de agravamento das condições materiais e da situação de vulnerabilidade familiar. Vejamos a tabela a seguir:

\section{Tabela 6}

\begin{tabular}{|l|c|c|c|c|c|c|c|}
\hline \multicolumn{1}{|c|}{ Quantidade de filhos por mulheres reeducandas (total das 68 mulheres mães) - CRF } \\
de Araraquara (2009) \\
\hline Número de mulheres-mães & 7 & 20 & 13 & 14 & 5 & 1 & 8 \\
\hline Quantidade de filhos & 1 & 2 & 3 & 4 & 5 & 9 & Não especificou \\
\hline
\end{tabular}

De acordo com a tabela, somente $10,29 \%$ das mulheres mães do CRF possuem um só filho, as demais possuem de dois a nove filhos, na sua maioria em idade escolar, até 18 anos.

Outro fator de preocupação é a guarda que, na maioria das vezes, é assumida por familiares mais próximos, principalmente avós maternos, seguidos dos pais, tia materna e avós paternos, de acordo com a pesquisa.

Os fatores ora apresentados se constituem na realidade vivenciada pelas mulheres reeducandas do CRF e influenciam significativamente tanto no processo de inserção no crime, como na ressocialização destas, quando do aprisionamento. 
A baixa escolaridade da população carcerária feminina nos remete a pensar sobre o papel da educação e qual sua efetividade no processo de ressocialização. Como já foi dito, a escolarização dentro da prisão tem como finalidade a formação das presas nos ensinos fundamental e médio e sua ressocialização do ponto de vista social, moral e ético. Como vimos nos dados apresentados, a educação influencia consideravelmente na vida profissional anterior ao período do cárcere. Educação, qualificação e trabalho são, portanto, os pilares da ressocialização. A elevação do nível escolar é essencial para que as apenadas consigam melhores oportunidades de trabalho e inserção social após o cumprimento de sua pena.

\section{Conclusão}

A abordagem do tema ressocialização, na perspectiva dos direitos humanos, tem como função trazer para a discussão atual o redimensionamento da política prisional e o grau de sua efetividade na redução dos danos sociais.

Não pretendemos desviar o enfoque, desconsiderando os atos violentos cometidos pelas presas condenadas, mas consideramos que a "reeducação" das infratoras só será alcançada com integração e inserção social dignas desses sujeitos, ou seja, quando o sistema conseguir absorver suas demandas por educação, saúde, moradia, vida digna, ou seja, seus sentimentos de pertencer, de fazer parte da sociedade.

O que verificamos hoje é que os delitos cometidos pela classe social mais abastada não são penalizados, pois esta possui recursos para sua defesa. A prisão hoje é uma instituição de criminalização da pobreza, uma vez que somente aquele que não possui conhecimento e recursos materiais para se defender é que acaba penalizado, muitas vezes com sentenças e julgamentos tardios e medidas punitivas severas à natureza do delito.

A privação da liberdade por meio do encarceramento não possibilita, por si só, a reeducação. Essa lógica perversa não é mais aceitável e se reflete na falência da política carcerária e no aumento da violência dentro dos presídios.

A educação voltada para a população carcerária feminina deve estar sensível às necessidades que esta população demanda, bem como 
deve possibilitar a desconstrução do sexismo enquanto relação de poder e subordinaçãa. Além disso, a educação deve se integrar a uma política séria de qualificação profissional e trabalho no cárcere. As atividades de trabalho e educação na prisão não podem ser encaradas como mais uma ocupação para a reeducanda cumprir seu tempo de pena mais tranquila, mas deve fazer parte de um projeto consistente de resgate da dignidade humana e possibilidade de novos sonhos e rumos, quando do cumprimento desta pena. A ação educativa como meio para a ressocialização deve resgatar a dignidade humana das mulheres presas, permitindo a atividade criadora e a construção da autonomia.

A falta de políticas públicas que auxiliem essas reeducandas póscumprimento da pena também é uma preocupação daqueles que trabalham com e em prol desse público. Pois a falta de oportunidades de trabalho, de vida digna, é que muitas vezes leva essas mulheres a se envolverem com o tráfico e a se identificarem com esse mundo que se apresenta, hoje, como garantia de dinheiro fácil e poder. Uma política educacional forte de valorização do sujeito e de sua autonomia, amparada por políticas públicas sérias de inserção social, econômica e política dessas mulheres, reduziria a possibilidade de retorno à prática de delitos.

Enquanto a sociedade não encarar os problemas que ela mesma cria, buscando mecanismos de humanização e inserção social de todos, por meio da redução da desigualdade social e econômica e de garantia de oportunidades dignas, o problema da violência continuará penalizando a todos, inclusive a esta mesma sociedade que se sente confortável em seu mundo de muros e câmeras de segurança, com medo de tudo que está fora dele.

Recebido em abril de 2010 e aprovado em agosto de 2010.

\section{Notas}

1. A esse respeito, ver Bourdieu (1989).

2. Sobre este tema, ver Habermas (1984) e Meillassoux (1976).

3. Atualmente, segundo dados do IBGE (PNAD, 2002), 30\% das famílias brasileiras são chefiadas por mulheres.

4. Sexismo é aqui entendido como o sistema de poder, inferioridade/superioridade entre homem e mulher, que impede a relação de igualdade entre os sexos. 
5. Goffman (1978, p. 11) define instituições totais como sendo “(...) local de residência e trabalho no qual um grande número de indivíduos com situação semelhante, separados da sociedade mais ampla por considerável período de tempo, levam uma vida fechada e formalmente administrada".

6. O exemplo mais significativo da história do Brasil com relação às formas de pseudocuidado e coisificação humana, e que até hoje marca as formas de relacionamento social, foi a escravidão, quando os escravos, no período imperial, considerados propriedade ou bem, foram a motivação de preocupações, inclusive jurídicas (Braunstein, 2007).

\section{Referências}

ADORNO, S. Ética e violência: adolescentes, crime e violência. In: Abramo, H.W.; Freitas, M.V.; Spósito, M.P. (Org.). Juventude em debate. São Paulo: Cortez, 2000. p. 97-110.

BOURDIEU, P. O poder simbólico. Lisboa: DIFEL, 1989.

BRASIL. Constituição (1988). Constituição da Republica Federativa do Brasil. São Paulo: Ática, 1990.

BRASIL. Lei n. 8.069, de 13 de julho de 1990. Dispõe sobre o Estatuto da Criança e do Adolescente e dá outras providencias. Diário Oficial da União, Brasília, DF, 16 jul 1990.

BRAUNSTEIN, H.R. Mulher encarcerada: trajetória entre a indignação e o sofrimento por atos de humilhação e violência. 2007. 174p. Dissertação (Mestrado) - Universidade de São Paulo, São Paulo.

BRITO, J. Trabalho e saúde nas indústrias de processos quimicos: a experiência das trabalhadoras. Rio de Janeiro: ENSP/FIOCRUZ, 1996.

CARVALHO FILHO, B.J. Depois dos muros e das grades: imagens e representações dos condenados sob livramento condicional e suas condições de sobrevivência. 2005. 245p. Tese (Doutorado) - Universidade Federal do Ceará, Fortaleza.

CUNHA, E.L. Trabalho feminino e instituição familiar: o papel dos indivíduos na esfera domestica. In: PAula, B.X. (Org.). Relações de trabalho e processos de exclusão na sociedade contemporânea: raça, gênero e geração. Franca: Ribeirão, 2007.

FOUCAULT, M. Vigiar e punir: o nascimento da prisão. Trad. de Raquel Ramalhete. 34. ed. Petrópolis: Vozes, 2007a. 
FOUCAULT, M. Microfísica do poder. Org. e trad. de Roberto Machado. 24. ed. Rio de Janeiro: Graal, $2007 \mathrm{~b}$.

FUNDAÇÃO DE AMPARO AO TRABALHADOR PRESO (FUNAP). "Fundação Prof. Dr. Manoel Pedro Pimentel". Disponível em: <http:// www.funap.sp.gov.br>. Acesso em: 3 fev. 2010.

GOFFMAN, E. Estigma: notas sobre a manipulação da identidade deteriorada. 2. ed. Rio de Janeiro: Zahar, 1978.

HABERMAS, J. Mudança estrutural da esfera pública. Rio de Janeiro: Tempo Brasileiro, 1984.

MARTINS, J.S. A sociedade vista do abismo: novos estudos sobre exclusão, pobreza e classes sociais. 3. ed. Petrópolis: Vozes, 2008.

MEILLASSOUX, C. Mulheres, celeiros \& capitais: crítica e sociedade. 7. ed. São Carlos: UfSCAR; Afrontamento, 1976.

NEVES, M.Y.R. Trabalho docente e saúde mental: a dor e a delicia de ser (tornar-se) professora. 1999. Tese (doutorado) - Universidade Federal do Rio de Janeiro, Rio de Janeiro.

PASCAL, M.A.M.; SCHWARTZ, R. Mulheres brasileiras: cotidiano, historia e conquistas. In: Pereira, B.R.; Nascimento, M.L.B.P. (Org.). Inclusão e exclusão: múltiplos contornos da educação brasileira. São Paulo: Expressão e Arte, 2006.

SENNETT, R. O talento e o fantasma da inutilidade. In: SEnNET, R. A cultura do novo capitalismo. Rio de Janeiro: Record, 2006.

SILVA, R. Os filhos do governo. São Paulo: Ática, 1997. (Fundamentos, 137). 